Elahe Aleebrahim-Dehkordi', Ebrahim Soleiman-Dehkordi ${ }^{1}$, Shirin Saberianpour ${ }^{2}$, Ali Hasanpour-Dehkordi $i^{3 *}$, Ayda Hasanpour Dehkordi ${ }^{4}$

\title{
CARE AND PREVENTION DURING THE COVID-19 PANDEMIC QUARANTINE: SEDENTARY LIFESTYLE AND INCREASED RISK OF KIDNEY STONES
}

\author{
${ }^{1}$ Medical Plants Research Center, Basic Health Sciences Institute, \\ Shahrekord University of Medical Sciences, Shahrekord, Iran \\ ${ }^{2}$ Vascular and Endovascular Surgery Research Center, Mashhad University of Medical Science, Mashhad, Iran \\ ${ }^{3}$ Social Determinants of Health Research Center, School of Allied Medical Sciences, \\ Shahrekord University of Medical Sciences, Shahrekord, Iran \\ ${ }^{4}$ Nickan Research Institute, Isfahan, Iran
}

*Corresponding author: ali20121968@yahoo.com

\begin{abstract}
Currently, the issue of lifestyle combined with lack of physical activity in quarantine conditions during the COVID-19 pandemic has become a major health problem in many countries around the world. Increased inactivity is associated with increased obesity as well as decreased physical activity and general health. Kidney stones are the third most common urinary tract disease. Prevention of non-communicable diseases depends on controlling risk factors such as low levels of physical activity. Kidney stones are also among the noncommunicable diseases that can be prevented by changing behavioral habits. Physical activity is a behavior that has many proven health benefits and is one of the most effective ways to prevent chronic diseases. The aim of this study was to investigate sedentary lifestyle and its relationship with oxidative stress and kidney stone formation, and finally to provide medical solutions and recommendations.
\end{abstract}

Keywords: Quarantine, SARS-CoV-2, COVID-19, Sedentary lifestyle, Oxidative stress, kidney stones

\section{Abbreviations:}

COVID-19: Coronavirus disease of 2019

SARS-CoV-2: Severe acute respiratory syndromerelated coronavirus-2

WHO: World Health Organization

IL-6: Interleukin 6

ARDS: Acute respiratory distress syndrome

TNF- $\alpha$ : Tumor necrosis factor

ROS: Reactive oxygen substance

RNS: Reactive nitrogen substance

CDC: Centers for Disease Control and Prevention

\section{INTRODUCTION}

Currently, what has caused fear and anxiety in different countries, it is new virus that was firstidentified in Wuhan. This new virus, entitled, Named COVID-19. Lack of treatment and Definitive prevention of the disease caused by this virus has caused a lot of stress and anxiety among people. Given that the only way to control COVID-19 is through public health measures, the disease has led to severe quarantine measures around the world in a short period of time $(1,2)$. with the widespread outbreak of coronavirus, followed by quarantine, and the restrictions that have been put in place have increased the incidence of chronic diseases $(3,4)$. Studies on inactivity and general health have shown that increased inactivity is associated with increased obesity as well as decreased physical activity and general health (5). Regular physical activity is essential for human health. And inactivity is a global problem in promoting public health, and is one of the ten leading causes of death in the world (6). Although proper physical activity is one of the easiest ways to stay healthy and experts emphasize increasing physical activity, with the outbreak of the COVID-19 virus, sedentary lifestyles have increased. Kidney stones are one of the most common diseases of the urinary system. The possible side effects of stones are also 
significant, therefore, early diagnosis and treatment of kidney and urinary tract stones and its excretion can prevent the enlargement of the stone and its subsequent complications. These rocks are composed of salts, especially phosphates or oxalates, or urea salts. The urinary stones form in the upper part of the urinary system and then move to the lower parts. The patient will not have any symptoms until these stones cause obstruction, but if the obstruction causes symptoms such as severe side pain, nausea, vomiting and blood in the urine. If the blockage is accompanied by infection, the patient may also have a fever and chills. If the disease is not controlled, the kidney is damaged and needs additional treatment, which in addition to severe pain, will cost a lot (7-9). People who lead sedentary lifestyles are more at risk for kidney stones. It seems that the best way to control kidney stones and their complications, especially in developing countries, is to prevent the growth of stones or the formation of new stones $(10,11)$. Currently, the issue of lifestyle combined with lack of physical activity in quarantine conditions during the Covid Pandemic has become a major health problem in many countries around the world. The aim of this study was to investigate sedentary lifestyle and its relationship with oxidative stress and kidney stone formation, and finally to provide medical solutions and recommendations.

\section{PHYSICAL INACTIVITY IN QUARANTINE DURING THE COVID-19 EPIDEMIC}

With the global epidemic of COVID-19 and the establishment of global quarantine in all countries in an effort to prevent the spread of coronavirus and a major problem of the destructive effects of quarantine on inactivity and physical activity is a threat to public health (12). However, along with creating this problem, people in developed countries have been allowed to exercise and do physical activity in the open air, which seems to reduce the stress of physical inactivity (13). The WHO has developed clear guidelines on the minimum physical activity necessary to maintain adequate health and fitness (14). It is recommended that adults between the ages of 18 and 64 (the age group most affected by recent COVID-19) should have at least 150 minutes of moderate-intensity physical activity or 75 minutes of vigorous physical activity per week (15). Limited physical activity with restrictions on regular walking from home due to severe quarantine in the elderly may be associated with adverse metabolic effects that significantly increase the risk of many severe and debilitating disorders such as diabetes, cancer, osteoporosis, disease, cardiovascular disease and kidney disease (16). In addition, decreased physical activity may affect a person's mental health, which may manifest as unpleasant feelings (17). In other studies, the destructive effects of acute cessation of physical activity, which occur after a sudden and severe quarantine, can be much more destructive (18). Abrupt cessation of exercise is associated with the rapid onset of insulin resistance in muscle tissue and decreased use of muscle glucose associated with muscle atrophy. Impaired aerobic activity and increased blood pressure reduce muscle energy expenditure, leading to the redistribution of metabolic substrates to the liver, where the production of atherogenic lipoproteins may be enhanced (19). On the other hand, in the position of reduced bad activity, cytokines IL-6 and TNF-a higher incidence of ARDS, compared to non-severe cases, indicate a greater inflammatory response (20). During quarantine we need to promote a healthy diet and physical activity at home. After quarantine, need to reevaluate Health of the cardiovascular system, kidneys, etc. in all age groups (21).

\section{FREE RADICALS (OXIDATIVE STRESS)}

Under natural conditions, between the production and elimination of free radicals, there is a balance. And the imbalance between the two indicates oxidative stress. In fact, oxidative stress is defined as a process that occurs due to an imbalance between the reactions that produce free radicals and the processes that neutralize these radicals $(22,23)$. Free radicals are compounds that are unstable. And are highly reactive. These compounds are ubiquitous and are usually derived from oxygen. They are also produced naturally in living cells, and their products increase under pathological conditions. Some types of free radicals, including superoxide dismutase and hydroxyl, are products of oxygen metabolism. Also, Hydrogen peroxide and peroxynitrite are capable of producing free radicals. Intracellular metabolism it causes ROS and RNS. ROS and RNS free radicals through oxidation of membrane lipids, Proteins and DNA cause cell damage $(24,25)$. Reaction between reactive oxygen metabolites and unsaturated lipids and as a result of their peroxidation, as one of the most significant biological damage is active oxygen metabolites. The increase in the production of free radicals is due to the increase in exposure to environmental oxidants and the increase in production in the body and the decrease in antioxidant capacity (26).

\section{PHYSICAL ACTIVITY AND ITS RELATIONSHIP WITH OXIDATIVE STRESS}

The type of physical activity performed plays an important role in the rate of oxidative damage and the body's defense response. Doing regular physical 
activity can act as a defense system and cause a positive regulation of the body's anti-oxidation systems (27). According to research, endurance training has been shown to prevent some of the symptoms of free radical scavenging. In contrast, free radical damage improves tissue antioxidant defenses by increasing the activity of antioxidants such as glutathione peroxidase and superoxide dismutase and catalase (28). the important point is that, However, not all research supports this and the response of different body tissues can be different. The production of free radicals seems to stimulate the antioxidant system to a certain extent, which can be considered as a cell defense mechanism. If the production of reactive oxygen species is too high, it can weaken the body's antioxidant system. Intense aerobic exercise, more than any other exercise, causes oxidative stress (29). So this point has to be taken into account, that physical activity and mobility is not just about doing strenuous activities, and the equilibrium limit must be considered. Maintaining an active lifestyle by doing daily activities, along with doing some gentle exercise, can help maintain good health. Also, regular physical activity is one of the ways to strengthen the immune system and prevent non-communicable diseases.

\section{SEDENTARY LIFESTYLE AND OBESITY AND ITS ASSOCIATION WITH KIDNEY STONE FORMATION}

According to the evidence and some studies on sedentary lifestyle and general health, increased inactivity has been shown to be associated with increased obesity. Because kidney stone disease is also affected by lifestyle changes and physical activity, sedentary lifestyle can lead to obesity and its consequences for other organs, including the kidneys. In addition, weight gain and obesity are important factors in the recurrence of urinary stones. Studies have shown that prolonged rest and inactivity lead to increased urinary calcium and subsequent formation of calcium oxalate and calcium phosphate crystals (3033). Evidence suggests that obesity and overweight play a greater role in stone formation than nutritional factors. Changes in body composition, expose a person to biophysical challenges associated with impaired regulation of temperature and body fluids. Due to the fact that body fat is hydrophobic, with increasing obesity, the total amount of water in the body decreases, thus it can cause dehydration. In addition, reducing the ratio of surface area to body volume disrupts heat exchange and the body's metabolism. Obesity causes an inflammatory condition in the body which upsets the electrolyte balance and changes the composition of the urine. These people are prone to developing uric acid stones. In general, the frequency of overweight and obese people in patients with kidney stones is very high. This indicates the role of weight gain and obesity in the formation of urinary stones. And supports the theory that in these people, due to increased secretion of uric acid and oxalate, an oversaturation of these salts occurs in the urine, which leads to the formation of their central nucleus (34-36).

\section{KIDNEY STONE DISEASE MANAGEMENT DURING THE COVID-19 EPIDEMIC}

The SARS-Cov-2 (COVID-19) epidemic is a social catastrophe and has a global impact on our life. While there are immediate challenges to prioritizing and increasing clinical activity (37). Urinary tract disease forms a significant part of the clinical burden of many urologists. Kidney stone disease is a crystal concretion formed usually within the kidneys. It is an increasing urological disorder of human health, affecting about $12 \%$ of the world population (38). It has been associated with an increased risk of end-stage renal failure. The etiology of kidney stone is multifactorial. To our knowledge, it is unknown whether decreased physical activity increases the risk of kidney stones. A recent observational study showed that in postmenopausal women increased physical activity and lower energy intake were associated with a significant reduction in the kidney stone risk (39). During CoV-2 (COVID-19) epidemic, the acuity of presentation can range from emergent (infected obstructing ureteral stones) to completely no urgent (no obstructing renal stones). Therefore, the health of the kidney system in people with kidney stones due to not having the necessary priority to go to the treatment department will be more endangered than ever (40). In this time Patients should follow the instructions considering principles of the Urological Association/End urological Society Surgical Management of Stones Guidelines (41).

\section{RECOMMENDATIONS OF SPORTS MEDICINE, WHO AND CDC IN QUARANTINE}

WHO considers it necessary to have adequate physical activity during quarantine to help maintain good health. Recommendations for increasing physical activity during outdoor quarantine include: Having a mask (extra carrying), proper disinfection, sunscreen, and drinking enough water during aerobic exercise are essential (42). before using the facility. Foreign sports that are needed should allow the previous person to leave and spend enough time disinfecting the area. When actively participating in group sports, there should be a distance of at least 6 
feet between individuals (43). Low-intensity exercise Emphasize covering and practicing social distance for low-intensity exercise (44). High-intensity exercise People who do strenuous activity, such as running, may not be able to wear a mask if they have difficulty breathing. If you cannot use a mask, do the activity in a place with more ventilation and air exchange (for example, outdoors in front of the house) and where you can maintain a physical distance from others (45). In situations where people may use loud noises, other people should wear exposed masks. It is not clear whether facial protectors provide benefits as a control source to protect others from inhaling particulate matter (46). However, the CDC does not recommend the use of face shields instead of masks for normal daily activities, and the use of masks is mandatory (47).

\section{CONCLUSION}

People who lead sedentary lifestyles are more at risk for kidney stones .In addition, weight gain and obesity are important factors in the recurrence of urinary stones. Obesity is also more involved in stone formation than nutritional factors. Exercise as one of the appropriate lifestyles is associated with favorable changes in blood pressure, fat metabolism and body weight. The type of physical activity performed plays an important role in the rate of oxidative damage and the body's defense response. Therefore, exercise should always be considered as an important and inseparable part of people's daily lives. And one of the effective ways to prevent it is to adjust your diet and lose weight through physical activity which effectively reduces the secretion of the main constituents of the stone. Therefore, with proper training to people in quarantine conditions, inactivity and obesity, followed by the formation of kidney stones can be prevented. It should be noted that physical activity, any daily life activity includes work tasks, housework and other daily tasks up to exercise.

\section{COMPETING INTERESTS}

The authors declare no competing interests.

\section{REFERENCES}

1. Brooks SK, Webster RK, Smith LE, et al. The psychological impact of quarantine and how to reduce it: rapid review of the evidence. The Lancet. 2020. Doi: 10.1016/S0140-6736 (20) 30460-8.

2. Taghdir M, Sepandi M, Abbaszadeh S, et al. A review on some Nutrition-Based Interventions in Covid-19. J Mil Med. 2020; 22(2):169-76. Doi: 10.30491/JMM.22.2.169.

3. Lim M, Huang I, Yonas E, et al. A wave of noncommunicable diseases following the COVID-19 pandemic. Diabetes Metab Syndr. 2020 September-October; 14(5): 979-980. Doi: 10.1016/j. dsx.2020.06.050. PMID: 32610263.

4. Palmer K, Monaco A, Kivipelto $\mathrm{M}$, et al. The potential long-term impact of the COVID-19 outbreak on patients with non-communicable diseases in Europe: consequences for healthy ageing. Aging Clin Exp Res. 2020; 32(7): 11891194. Doi: 10.1007/s40520-020-01601-4. PMID: 32458356.

5. Pietiläinen K, Kaprio J, Borg P, et al. Physical inactivity and obesity: A vicious circle. Obesity (Silver Spring). 2008 Feb; 16(2): 409-414. Doi: 10.1038/oby.2007.72. PMID: 18239652.

6. Kohl H.W, Craig C.L, Victoria Lambert E, et al. The Pandemic of Physical Inactivity: Global Action for Public Health. The Lancet. 2012; 380 (9838):294305. DOI: 10.1016/S0140-6736(12)60898-8.

7. Khazaei S, Mohammadian Hafshejani A, Saatchi $\mathrm{M}$, et al. Epidemiological Aspects of Cutaneous Leishmaniasis in Iran. Arch Clin Infect Dis. 2015; 10(3):e28511. Doi: 10.5812/archcid.28511.

8. Stamatelou KK, Francis ME, Jones CA, et al. Time trends in reported prevalence of kidney stones in the United States: 1976 -1994. Kidney Int. 2003; 63(5):1817-23. doi: 10.1046/j.15231755.2003.00917.x.

9. Vupputuri S, Soucie JM, McClellan W, et al. History of kidney stones as a possible risk factor for chronic kidney disease. Ann Epidemiol. 2004; 14: 222-228. DOI: 10.1016/S1047-2797(03) 001261.

10. Hwang TI, Hill K, Schneider V, et al. Effect of prolonged bed rest on the propensity for renal stone formation. J Clin Endocrinol Metab. 1988; 66:109-112. https://doi.org/10.1210/jcem-66-1-109.

11. Sas DJ. An update on the changing epidemiology and metabolic risk factors in pediatric kidney stone disease. Clin J Am Soc Nephrol. 2011; 6:20622068. DOI: https://doi.org/10.2215/CJN.11191210.

12. Nodoushan JR, Alimoradi H, Nazari $M$. Investigating the Effect of COVID-19 on Spiritual Health and Stress of Pregnant Women. 2020. DOI: https://doi.org/10.21203/rs.3.rs-74878/v1.

13. Woods JA, Hutchinson NT, Powers SK, et al. The COVID-19 pandemic and physical activity. J SMHS. 2020; 2 (2): 55-65. https://doi.org/10.1016/j. smhs.2020.05.006.

14. Martin Ginis, Kathleen A, Christopher R. West. From guidelines to practice: evelopment and implementation of disability-specific physical activity guidelines. Disabil Rehabil. 2020; 1-8. https://doi.org/10.1080/09638288.2020.1757167. 
15. Limbers CA, McCollum C, Greenwood E. Physical activity moderates the association between parenting stress and quality of life in working mothers during the COVID-19 pandemic. Ment Health Phys Act. 2020; 19 (2020) 100358. https:// doi.org/10.1016/j.mhpa.2020.100358.

16. Sheikhhoseini R, Sayyadi P, Piri H. The Use of Technology in Quarantine: A Way to Maintain and Promote Physical Health. New Approaches in Sport Sciences (NASS) 2020; 2 (3):1-14. DOI: 10.22054/nass.2020.53039.1062.

17. Singh, Shweta, et al. Impact of COVID-19 and lockdown on mental health of children and adolescents: A narrative review with recommendations. Psychiatry Res. 2020; 293: 113429. doi: 10.1016/j.psychres.2020.113429. PMID: 32882598.

18. Curby DG. COVID-19: Considerations regarding the return to wrestling training. Int. J. Wrestl. Sci. 2020; 10 (1), 1-14. Access: 13.10.2020 at http:// inwr-wrestling.com/wp-content/uploads/2020/10/ Full-Issue.pdf.

19. Grundy, Scott M. Metabolic syndrom update. Trends Cardiovasc Med. 2016;26(4):364-73. doi: 10.1016/j.tcm.2015.10.004

20. Lingeswaran, Malavika, et al. Inflammation, Immunity and Immunogenetics in COVID-19: A Narrative Review. Indian J. Clin. Biochem. 3(35): 260-273, 20200701.

21. Saha S, Tinni D. A study on the psychological crisis during the lockdown caused due to covid-19 pandemic. Afr. J. Biochem. Res. 2020; 3(2):41-49.

22. Aleebrahim-Dehkordy E, Khodadadi S, Mousavipanah Z, Nasri H. Herbal antioxidants and kidney. Ann Res Antioxid. 2016;1(1):e08.

23. Niatsetskaya ZV, Sosunov SA, Matsiukevich D, Utkinasosunova IV, Ratner VI, Starkov AA. The oxygen free radicals originating from mitochondrial complex I contribute to oxidative brain injury following hypoxia ischemia in neonatal mice. J Neurosci.2012 29; 32:3235-44.

24. Bickers DR, Athar M. Oxidative stress in the pathogenesis of skin disease. J. Investig. Dermatol. 2006, 126, 2565-2675.

25. Birben E, Sahiner UM, Sackesen C et al. Oxidative stress and antioxidant defense. World Allergy Organ J. 2012; 5, 9-19. https://doi.org/10.1097/ WOX.0b013e3182439613.

26. Valko M, Leibfritz D, Moncol $J$ et al. Free radicals and antioxidant in normal physiological functions and human disease. Int J Biochem Cell B. $2007 ; 39$ (1): 44-84. https://doi.org/10.1016/j. biocel.2006.07.001.

27. Revan S, Erol A. Effects of endurance training on exhaustive exercise induced oxidative stress markers. Afr. J. Pharm. Pharmacol. 2011;5(3):43741. DOI:10.5897/AJPP11.159.
28. Modir M, Daryanoosh F, Tanideh N, et al. The effects of short and middle time's aerobic exercise with high intensities on ingredients antioxidant in female Sprague Dawley rats. J Mash had Univ Med. 2014; 57(3):587-95. 10.22038/MJMS.2014.3017.

29. Afzalpour M, M S, A Z, M J. Comparison of the effects of an acute resistance and aerobic exercise session on the antioxidant defense system and lipid peroxidation of healthy young men. J. Sports Biomotor Sci. 2012; 6(2):39-50.

30. Liu J, Cao, Z, Zhang Z. et al. A comparative study on several models of experimental renal calcium oxalate stones formation in rats. J. Huazhong Univ. Sc. Technol. 2007; 27, 83-87. https://doi. org/10.1007/s11596-007-0124-z.

31. Rost R, Steinacker J.M. Sport- und Bewegungstherapie bei Inneren Krankheiten. Sportwiss. 1998; 28, 454-456. https://doi. org/10.1007/BF03176524.

32. Johnson CM. Renal Stone epidemiology: a25-year study in Rochester - Minnesota. Kidney Int. 2006; 16 (5):623-624. https://doi.org/10.1038/ki.1979.173.

33. Tsujihata M. Mechanism of calcium oxalate renal stone formation and renal tubular cell injury. Int. J. Urol. 2008; 15:115-120. https://doi.org/10.1111/ j.1442-2042.2007.01953.x.

34. Frassetto L, Kohlstadt I. Treatment and prevention of kidney stones: an update. Am Fam Physician. 2011; 84 (11):123-124.

35. Alelign T, Petros B. Kidney Stone Disease: An Update on Current Concepts. Adv Urol. 2018; 2018: 3068365. doi: 10.1155/2018/3068365. PMID: 29515627

36. Sohgaura A, Bigoniya P. A Review on Epidemiology and Etiology of Renal Stone. Amer J Drug Disc Devel. 2017; 7: 54-62. DOI: 10.3923/ ajdd.2017.54.62

37. Sultana J, Mazzaglia G, Luxi N. et al. Potential effects of vaccinations on the prevention of COVID-19: rationale, clinical evidence, risks, and public health considerations. Expert Rev. Vaccines. 2020; 1-18. https://doi.org/10.1080/14760584.2020. 1825951.

38. Rodriguez Cuellar CI, Wang PZ, Freundlich M, et al. Educational review: role of the pediatric nephrologists in the work-up and management of kidney stones. Pediatr Nephrol. 2020; 35, 383-397. https://doi.org/10.1007/s00467-018-4179-9.

39. Khoshdel-Rad N, Zahmatkesh E, Shpichka A, et al. Outbreak of chronic renal failure: will this be a delayed heritage of COVID-19?. J Nephrol. 2021; 34, 3-5. https://doi.org/10.1007/s40620-020-008519.

40. Stephens A. Extreme heat and kidney-related emergency room use in Nevada. Retrieved from: https://doi.org/doi:10.7282/t3-fysw-xv96 
41. Abstracts of the ASMA scientific sessions 2012. Workshop: aircrew fatigue: causes, consequences, and countermeasures. Aviation, Space, and Environmental Medicine 2012; Vol. 83, No. 3

42. World Health Organization. Considerations for implementing and adjusting public health and social measures in the context of COVID-19: interim guidance, 4 November 2020. No. WHO/2019nCoV/Adjusting_PH_measures/2020.2. World Health Organization, 2020.

43. Saurin TA. A complexity thinking account of the COVID-19 pandemic: implications for systemsoriented safety management. Saf. Sci. 2021; 134 105087, https://doi.org/10.1016/j.ssci.2020.105087.

44. Kara E. Coronavirus (COVID-19) pandemic: Immunity and exercise intervention. Int. J. Appl. Exerc. Physiol. 2020; 9 (10), 97-104. Access 29.10.2020 at http://ijaep.com/Journal/vol.9.10.

45. Keskinen K.E, Gao Y, Rantakokko M, et al. Associations of Environmental Features with
Outdoor Physical Activity on Weekdays and Weekend Days: A Cross-Sectional Study among Older People. J Frontiers Public Health. 2020. 8, 578275. DOI: $10.3389 /$ fpubh.2020.578275

46. Shen H, Liu B, Chen Y, et al. Individual and population level protection from particulate matter exposure by wearing facemasks. Environ Int. 2021; 146, 106026. https://doi. org/10.1016/j. envint.2020.106026.

47. Zhang M, Robert Emery A, Tannyhill RJ, et al. Surgical Masks or N95 respirators for OMF Surgery during COVID-19 pandemic. J Oral Maxillofac Surg. 2020; 78(12): 2114-2127. DOI: 10.1016/j.joms.2020.08.024

Received: 8.04.2021

Accepted for publication: 13.05.2021

Address for correspondence:

ali20121968@yahoo.com 